\title{
Science, Myth, and the Mangement of Natural Resources
}

\author{
Frederick D. Provenza
}

In what follows, I draw a distinction between reductionist science that accents parts and systems science that accents wholes. I conclude that both views are deeply interrelated, and that neither position alone will solve the problems we face today. Science provides understanding of processes, but it can only provide likelihoods of behaviors of systems, given sets of conditions, none of which are known absolutely. Moreover, science only elucidates what is, not what ought to be.

In the preface to his book The Marriage of Sense and Soul: Integrating Science and Religion, Ken Wilber (1999) points out that "There is a strange and curious thing about scientific truth. As its own proponents constantly explain, science is basically value-free. It tells us what is, not what should be or ought to be. An electron isn't good or bad, it just is; the cell's nucleus is not good or bad, it just is; a solar system isn't good or bad, it just is. Consequently science, in elucidating or describing these basic facts about the universe, has virtually nothing to tell us about good or bad, wise or unwise, desirable and undesirable. Science might offer us truth, but how to use that truth wisely: on this science is, and always has been, utterly silent."

Only people can reconcile science with different valuescultural, economic, and ecological—to manage systems. We must seek innovative solutions, through science and empathy for others, to the problems that arise when peoples with different values attempt to use land. Our strength, and only hope, is for peoples of disparate beliefs to work together. That doesn't mean giving up individual views-our differences are our strength. Rather, it means building shared visions by opening up to one another from the heart. Ultimately, creativity comes from unions of opposites.

\section{Reductionist Science}

Modern science uses experimentation, replication of results, analysis of cause and effect, and factual documentation to test hypotheses. The scientific method is a belief not in any specific theory or body of facts but in a process through which we conduct the search for truth. At its best, it is the study of processes of nature, which involves a journey into the unknown to discover the ongoing workings of nature.

Three interrelated "methods" are used repeatedly in the quest for truth (Romesburg 1981). Individual research programs, as well as disciplines, are built on these three pillars. Induction involves discovering what is happening. It is based on observation - the keener the better-of events and patterns in nature. Retroduction involves hypothesizing how and why events and patterns happen. The more insightful the hypothe- ses, and the more of them, the better. Hypothetico-deduction involves experimentation to test alternative hypotheses concerning the workings of nature. The experiments consist of tests of predictions that stem from hypotheses about natureif nature works in this way, then I expect such and such to happen. Experiments determine if "such and such" actually happens given particular sets of circumstances. The "cleaner" the experiments - the more variables controlled - the better.

Unfortunately, even the best experiments are merely snapshots in time of an ongoing dynamic. To conduct a "good" experiment, we must attempt to stop the clock-hold everything constant. In fact, no experiment has ever controlled all the variables. In any study of behavior, for example, both the lack of experience and the presence of experience influence the outcome of the experiment. Thus, whether or not a creature has experience isn't the issue. The real issue is understanding how experience influences the outcome of the experiment, and putting the study into a broader context. In fact, the more one learns about behavior, the more one sees that everything is connected to everything else in time and space (Provenza et al. 1998).

Reductionist science stands out as one of the millennium's most powerful belief systems. The knowledge that has accumulated from understanding parts has lead to revolutions in all facets of life from biology (e.g., modern medicine) to technology (e.g., man on the moon). Our understanding of nature had been a direct result of continually attempting to understand how parts of systems work-from differentiating.

"All natural and healthy growth proceeds," as Ken Wilber (1999) suggests, "by differentiation-and-integration. The clearest example of this is the growth of a complex organism from a single-celled egg: the zygote divides into two cells, then four, then eight, then sixteen, then thirty-two...into literally millions of cells. And while this extraordinary differentia tion is occurring, the different cells are simultaneously being integrated into coherent tissues and systems in the overall organism. This differentiation-and-integration process allows a single cell to evolve into a multicellular organism and complex system of exquisite unity and functional integrity."

Differentiation is both the strength and the weakness of reductionist science. Differentiation carried to an extreme results in fragmentation of information and knowledge. Disciplines become dissociated, isolated empires unto themselves. This has drawn the criticism that reductionist science provides ever more information about less and less until we know everything about nothing. But differentiation is only a weakness when we fail to integrate across ever more narrowly defined sub-disciplines. Differentiation is a strength-the fabric wove of parts and mechanisms-when we understand in- 
terrelationships across space and time. Thus, the age-old debate between holism and reductionism is misguided because it fails to discriminate differentiation from integration. The problem today is lack of integration, not lack of differentiation. Systems views in science and management accent inte gration.

\section{Systems Views}

Systems thinking is an attempt to integrate parts to reveal the workings of wholes. According to a systems view, seemingly distinct components of systems - each described by the term "holon" (Hollick, 1993)_interact to create global behavior without comprehensive or global knowledge by any of the component parts. A holon is an autonomous entity when viewed from its constituent subsystems - an individual from the perspective of an organ or cell-but from another perspective, it is merely a component of a larger system-an individual as a member of a social group or as a component of a physical landscape. A holon's behavior influences behavior at larger scales, which in turn influences behavior at smaller scales. Parts create wholes which recreate parts which recreate wholes.....and everything is a holon.

Scientific understanding of behavior and its application to management is an exercise in comprehending relationships among parts and wholes (Provenza et al. 1998). Behavior is an integration of the circle of life-gametes create cells create organs create individuals create social groups all of which influence environments influence social groups influence individuals influence organs influence cells influence gametes. Individuals are strands in the web of society, but at the same time they are societies of cells variously arranged "internally" into organs and organ systems that interact with one another and the "external" social and physical environments, to the extent that it is difficult to clearly define an individual. At all levels of organization, behavior depends on consequences that involve ongoing integration of information across levels of resolution from cells and organs to social and physical environments. In that sense, the notion of cause-and-effect is replaced with functional relationships between behaviors and consequences. Simply put, as the world changes, being gives way to becoming and the illusion of arriving yields to the experience of the journey.

Dynamic complexity arises from endless interactions among holons - self-balancing and self-reinforcing feedback loops that are non-linear and difficult to predict (Provenza et al. 1998). Climate, soils, plants, herbivores, and people, for example, are interrelated facets of systems that change constantly. Ongoing change requires each component of the system to continually adapt.

Systems thinking focuses on understanding systemic processes-systems archetypes-that result in emergent patterns over time and space (Senge1994). In so doing, it seeks longer-term solutions to underlying problems, as opposed to shorter-term fixes that mainly consider symptoms. Systems views emphasize circles and non-linear interconnections as ways of understanding, as opposed to linear ways of thinking. One comes to realize that everything involves circular arrangements of influence in play over time and space.
Behavioral escalations - such as marriage quarrels, the arms race, and arguments over natural resources - are one example.

Viewed from only one perspective, the relationship appears to be linear:

My view: your aggression $\longrightarrow$ threat to me $\longrightarrow$ I counter Your view: my aggression $\longrightarrow$ threat to you $\longrightarrow$ you counter

But in fact, it is a self-reinforcing circle, with players on both sides involved.

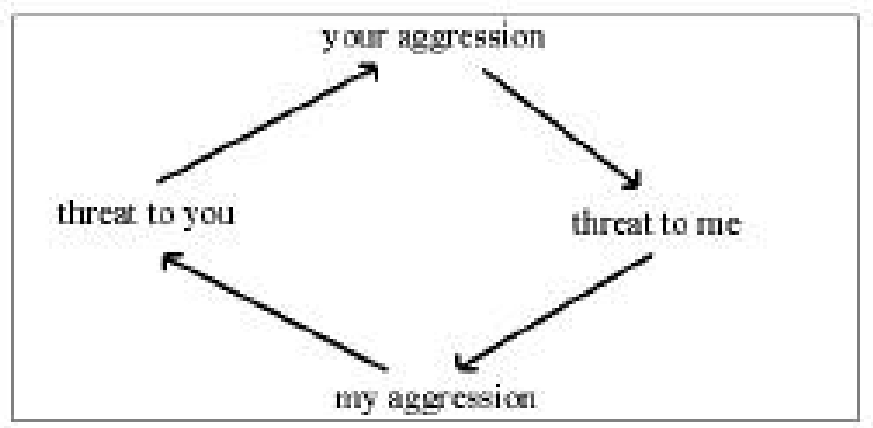

Systems thinking complicates ethical issues over responsibility. It is impossible to assign strictly linear cause-and-effect relationships to anything or anyone in the conventional sense. Every act is influenced by so many factors in play over time and space that we can't really assign cause. Who is to blame for the arms race or fights over land? In mastering systems thinking, we give up the assumption that there is an individual, or an individual agent, responsible. The feedback perspective suggests everyone shares responsibility for problems generated by a system, be that interrelationships in marriages, on rangelands, or among nations (Senge 1994).

Some of the oldest belief systems on the planet have embraced the notion of interconnectedness implicit in systems views. These sentiments are tacit in the Eastern world view, as Lama Anagarika Govinda observes, "The Buddhist does not believe in an independent or separately existing external world, into whose dynamic forces he could insert himself. The external world and his inner world are for him only two sides of the same fabric, in which the threads of all forces and of all events, of all forms of consciousness and of their objects, are woven into an inseparable net of endless, mutually conditioned relations." (from Capra 1991). These same views reverberate in the words of Chief Seattle to the "Great Chief in Washington" in 1854, "This we know: The earth does not belong to man; man belongs to the earth. This we know. All things are connected like the blood that unites one family. All things are connected. Whatever befalls the earth befalls the sons of the earth. Man did not weave the web of life; he is merely a strand in it. Whatever he does to the web, he does to himself."

Age-old philosophies also underscore the dynamics of life. Eastern mystics see the universe as an inseparable web, whose interconnections are dynamic, moving, changing constantly. In Chinese philosophy, the flowing and ever-changing reality is called the Tao and is seen as a cosmic process in which all things are involved. Taoists say one should adapt one's actions to the flow of life. Buddhists call this world of ceaseless change samsara, which means 'incessantly in motion'. They, too, strive to move with the flow of life. "The central idea of Kegon," as 
D.T. Suzuki suggests, "is to grasp the universe dynamically whose characteristic is always to move onward, to be forever in the mood of moving, which is life." (from Capra 1991).

The same sentiments-interconnectedness and change-are echoed from a scientific view by the eminent physicist John Archibald Wheeler, "Nothing is more important about the quantum principle than this, that it destroys the concept of the world as 'sitting out there,' with the observer safely separated from it by a 20 centimeter slab of plate glass. Even to observe so minuscule an object as an electron, he must shatter the glass. He must reach in. He must install his chosen measuring equipment... Moreover, the measurement changes the state of the electron. The universe will never afterwards be the same. To describe what has happened, one has to cross out that old word 'observer' and put in its place the new word 'participator'. In some strange sense the universe is a participatory universe." (from Capra 1991).

The German philosopher Arthur Schopenhauer accents these truths for the individual in an essay titled $O n$ an Apparent Intention in the Fate of the Individual. He points out that "when you reach an advanced age and look back over your lifetime, it can seem to have had a consistent order and plan, as though composed by some novelist. Events that when they had occurred had seemed accidental and of little moment turn out to have been indispensable factors in the composition of a consistent plot. So who composed that plot? Schopenhauer suggests that just as your dreams are composed by an aspect of yourself of which your consciousness is unaware, so, too, your whole life.... And just as people whom you will have met apparently by mere chance became leading agents in the structuring of your life, so, too, will you have served unknowingly as an agent, giving meaning to the lives of others. The whole thing gears together like one big symphony, with everything unconsciously structuring everything else. And Schopenhauer concludes that it is as though our lives were the features of the one great dream of a single dreamer in which all the dream characters dream, too; so that everything links to everything else, moved by the one will to life which is the universal will in nature." (quoted from a summary of Schopenhauer's essay by Joseph Campbell in The Power of Myth - Campbell and Moyers 1988).

\section{Implications}

Interconnectedness and dynamism-history, necessity, chance-influence system behavior over time and space, and they make the behavior of every holon unique and context dependent. Thus, it is impossible to generalize from time to time and place to place. Virtually anything is possible given different combinations of climate, soils, plants, animals, and people. As Ken Wilber (1999) points out, "....contexts are indeed boundless precisely because reality is composed of holons within holons within holons indefinitely, with no discernable bottom or top. Even the entire present universe is simply a part of the next moment's universe. Every whole is always a part, endlessly. And therefore every conceivable context is boundless."

That's why "controlled experiments" are not a good tool to investigate various management options, for example, to com- pare landscape level manipulations such as different grazing systems. Monitoring the ongoing dynamic under different management scenarios is more important than "testing hypotheses" under supposedly controlled conditions to determine what causes what.

That doesn't mean that we can't discern patterns. Nor does it mean that we can't understand how nature works. The processes are knowable, and given particular contexts, certain patterns are more likely than others (Senge 1994). It implies, however, that we may never be able to predict outcomes due to the dynamism, complexity, and indeterminacy of the processes. As contingencies change, so too patterns and events. We will always make decisions in the face of uncertainty. Life is an ongoing series of choices in the face of varying degrees of uncertainty.

That notion was the realization at the turn of the 20th century when the views of physicists underwent radical transformations, from fairly rigid Newtonian beliefs that nature is knowable and predictable, if we can just discover the rules, to probabilistic notions of quantum mechanics, which illustrate that nature is knowable but not predictable even if we know the rules, to relativistic concepts of time and space that show the processes of nature are relative to the observer (Provenza et al. 1999). Just as physicists have been forced to relinquish their rigid Newtonian views, researchers and managers of natural resource systems must eventually abandon inflexible perspectives for ones that reflect the dynamics of life.

Twentieth-century physics has shown that there is no absolute truth in science, that all concepts and theories are limited and approximate. Science is a quest for understanding, for truth, an attempt to account for observable phenomena in the physical and biological worlds, but science can not be perceived as "true" or "final" in any absolute sense. It is merely a tentative organization of working hypotheses that, for the moment, best account for the facts concerning physical and biological processes whose interconnections are the fabric of a web characterized by change.

Twentieth-century managers confront a similar challenge: How does one manage ongoing interrelationships among facets of complex and poorly understood ecological, cultural, and economic systems, in light of a future not known and not necessarily predictable, in ways that won't diminish options for future generations?

Ongoing adaptation in the face of change is the essence of life for all creatures, including scientists and managers. In that sense, scientists and managers ought to accent understanding and adaptation-explore, implement, monitor, adapt...rather than prediction. In the arena of constant transformation, virtually anything is possible if we dare to engage one another and the environment in ways that nurture creativity.

Creativity comes from venturing into the unknown. The familiar - typically comforting, orderly, and predictable - is at the same time often devoid of creative zeal. The unfamiliarusually obscure, potentially dangerous, always unpredictable is pregnant with creative opportunities. Creativity comes from unions of opposites, from compassion, from opening up to that which is different from oneself. The courage to love is the courage to transcend tradition. The contemporary world of natural resource management is filled with passion, but devoid of compassion. The challenge is to transcend the boundaries 
we create. "All boundaries" as Peter Senge (1994) suggests, "are fundamentally arbitrary. We invent them and then, ironically, we find ourselves trapped within them." Compassion for others is the way to transcend boundaries, to find the center that lies beyond pairs of opposites.

\section{Conclusion}

Against a backdrop of ceaseless change, controversies over land-whose resources and for what use-remain steadfastly unchanged. The Buddha taught that "all compounded things are impermanent." All suffering arises from trying to cling to fixed forms - objects, people, ideas. The challenge is to accept the world as it moves and changes. The solution lies not in more science or better management-reductionist or holist. Rather, the solution lies in integrating ecological, cultural, and economic values and beliefs of peoples from vastly different backgrounds. To do so, we must all transcend boundaries fears, desires, social duty - all the time.

Joseph Campbell (1988) concluded an essay on "The Impact of Science on Myth" with a Hindu legend that depicts how "gods" transcend the boundaries to cope with the challenges, dilemmas, and transformations of life. The myth tells "of a time at the very start of the history of the universe when the gods and their chief enemies, the anti-gods, were engaged in one of their eternal wars. They decided this time to conclude a truce and in cooperation to churn the Milky Ocean-the Universal Sea-for its butter of immortality. They took for their churning-spindle the Cosmic Mountain (the Vedic counterpart of Dante's Mountain of Purgatory), and for a twirlingcord they wrapped the Cosmic Serpent around it. Then, with the gods all pulling at the head end and the anti-gods at the tail, they caused that Cosmic Mountain to whirl. And they had been churning thus for a thousand years when a great black cloud of absolutely poisonous smoke came up out of the waters, and the churning had to stop. They had broken through to an unprecedented source of power, and what they were experiencing first were its negative, lethal effects. If the work were to continue, some one of them was going to have to swallow and absorb that poisonous cloud, and, as all knew, there was but one who would be capable of such an act; namely, the archetypal god of yoga, Shiva, a frightening demonic figure. He just took that entire poison cloud into his begging bowl and at one gulp drank it down, holding it by yoga at the level of his throat, where it turned the whole throat blue; and he has been known as Blue Throat, Nilakantha, ever since. Then, when that wonderful deed had been accomplished, all the other gods and the anti-gods returned to their common labor. And they churned and they churned and they went right on tirelessly churning, until lo! a number of wonderful benefits began coming up out of the Cosmic Sea: the moon, the sun, an elephant with eight trunks came up, a glorious steed, and certain medicines, and yes, at last! a great radiant vessel filled with the ambrosial butter."

Joseph Campbell offered this ancient Indian myth as a parable for our world today, as an exhortation to press on with the work, beyond fear. It is as relevant today as it was eons ago when the gods and anti-gods decided to conclude a truce and in cooperation churn the Milky Ocean for its butter of immor-

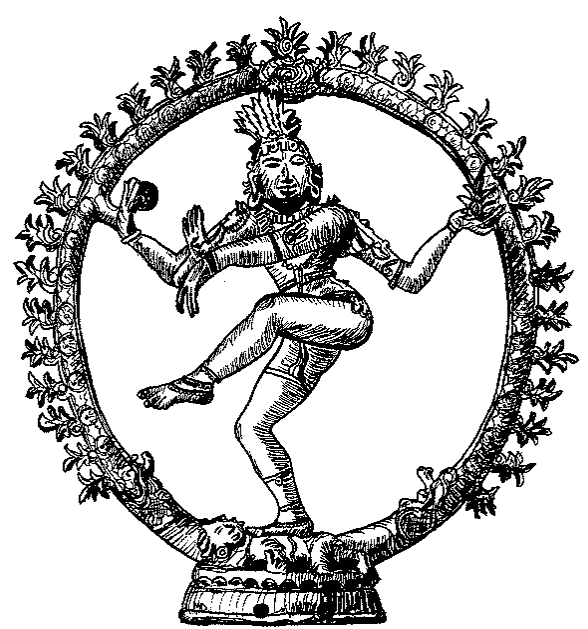

Fig. 1. Shiva, lord of the dance.

tality. For according to Hindu thinking, we are the gods and the anti-gods-pairs of opposites in the field of time and space. And through his dance, illustrated in Figure 1, the Indian god Shiva symbolizes the manifold phenomena in the world. He unifies all things by immersing them in his rhythm and making them participate in the dance, a magnificent image of the dynamic unity of the universe. In his right hand a drum, the tick, tick, tick of time. In his left hand a flame, existence in the process of becoming. His earrings, symbolic of the pairs of opposites, as the Greek gods Apollo and Dionosis symbolize light and dark. Apollo, the god of the light, represents the beauty of the moment and fixed forms. Dionysos, the god of the dark, destroys the old forms in order to bring forth new forms. Shiva, encircled by flames, is serene and still amidst the dynamism of creation and destruction. Everything contains its opposite, and at the center, all is still.

\section{References}

Campbell, J. 1988. Myths to Live by. Viking Penguin Inc., New York. Campbell, J. and B. Moyers. 1988. The Power of Myth. Doubleday, New York.

Capra, F. 1991. The Tao of Physics. Shambhala, Boston.

Hollick, M. 1993. Self-organizing systems and environmental management. Environmental Management 17:621-628.

Provenza, F.D., J.J. Villalba, C.D. Cheney and S.J. Werner. 1998. Self-organization of foraging behaviour: From simplicity to complexity without goals. Nutr. Res. Rev. 11: 199-222.

Provenza, F.D., J.J. Villalba and M. Augner. 1999. The physics of foraging. Volume III, Pages 99-107 in J.G. Buchanan-Smith, L.D Bailey and P. McCaughey (eds.) Proceedings of the XVIII International Grassland Congress. Extension Service, Saskatchewan Agriculture \& Food. Saskatoon, Saskatchewan.

Romesberg, H.C. 1981. Wildlife science: gaining reliable knowledge. J. Wildl. Manage. 45:293-313.

Senge, P.M. 1994. The Fifth Discipline: The Art \& Practice of The Learning Organization. Currency Doubleday, New York.

Wilber, K. 1999. The Marriage of Sense and Soul: Integrating Science and Religion. Broadway Books, New York.

The author is with the Department of Rangeland Resources, Utah State University, Logan, Utah 84322-5230. 